\title{
Patients' views of involuntary hospital admission after 1 and 3 months: prospective study in 11 European countries
}

\author{
Stefan Priebe, Christina Katsakou, Matthias Glöckner, Algirdas Dembinskas, Andrea Fiorillo, \\ Anastasia Karastergiou, Andrzej Kiejna, Lars Kjellin, Pitr Nawka, George Onchev, Jiri Raboch, \\ Matthias Schuetzwohl, Zahava Solomon, Francisco Torres-González, Duolao Wang and Thomas Kallert
}

\section{Background}

Legislation and practice of involuntary hospital admission vary substantially among European countries, but differences in outcomes have not been studied.

\section{Aims \\ To explore patients' views following involuntary hospitalisation in different European countries.}

\section{Method}

In a prospective study in 11 countries, 2326 consecutive involuntary patients admitted to psychiatric hospital departments were interviewed within 1 week of admission; 1809 were followed up 1 month and 16133 months later. Patients' views as to whether the admission was right were the outcome criterion.

\section{Results}

In the different countries, between 39 and $71 \%$ felt the admission was right after 1 month, and between 46 and 86\% after 3 months. Females, those living alone and those with a diagnosis of schizophrenia had more negative views. Adjusting for confounding factors, differences between countries were significant.

\section{Conclusions}

International differences in legislation and practice may be relevant to outcomes and inform improvements in policies, particularly in countries with poorer outcomes.

\section{Declaration of interest}

None.
Throughout the world significant numbers of people are admitted involuntarily to psychiatric hospital departments. How involuntary hospital admissions should best be legislated for and regulated is controversial. ${ }^{1-3}$ In the UK, the government has proposed two bills for a new mental health act in England and Wales since 2002. Following the wide resistance of professional groups, user organisations and parts of the media, both bills were withdrawn and the government settled for an amendment to the existing 1983 Act. $^{4,5}$

The debate on the most appropriate regulations and practice for involuntary hospital admission is guided by little, if any, research. There is no evidence about whether specific procedures are associated with different outcomes. ${ }^{6,7}$ Ethical and practical reasons may prevent experimental designs such as randomised controlled trials. In their absence, observational comparisons between sites with different legislation and practice are a viable method to explore the link between procedures and outcomes.

Countries across Europe share a similar background in terms of societal systems and history of psychiatry but vary substantially in their legislation for and practice of involuntary hospital admission. ${ }^{8,9}$ Involuntary admission rates vary by a factor of more than 10. ${ }^{1,10}$ Several studies have analysed the differences in legislation and policies but there is no evidence yet on whether there also are differences in outcomes.

Legislation for involuntary admissions is based on the assumption that individuals cannot recognise the need for hospital care because of the severe and usually acute symptoms of their illness. This would imply that they should later (once the acute phase is over) accept that the involuntary admission was the right intervention at the time. ${ }^{11}$ Patients' retrospective view of the appropriateness of the admission has been used as an outcome criterion in studies in Australia, Canada, Sweden, the USA and the UK. ${ }^{12-18}$ Between 33 and $81 \%$ of involuntary patients found the admission 'right' in retrospect. The rate varied according to the exact wording of the question and the time since admission. $^{6}$

In this study we assessed patients' views on involuntary hospital admission after 1 and 3 months at sites in 11 European countries. We explored whether, and if so, to what extent, patients' retrospective views on admission varied between sites in different countries, whether these differences held true after controlling for differences in patient characteristics and what baseline patient characteristics were associated with more or less positive views across countries.

\section{Method}

\section{Design and participants}

The study was conducted as a multicentre prospective cohort study in 11 European countries: Bulgaria (Sofia), Czech Republic (Prague), Germany (Dresden), Greece (Thessaloniki), Italy (Naples), Lithuania (Vilnius), Poland (Wrocław), Slovakia (Michalovce), Spain (Granada and Malaga), Sweden (Örebro) and the UK (east London). Between one and five hospitals were studied in each country. Tel Aviv in Israel was originally included, but omitted from this analysis because of inadequate study implementation. All sites had in-patient units with voluntary as well as involuntary patients. Involuntary admissions were conducted according to national legislation and routine practice. The rationale and methods of the study, the characteristics of the participating hospitals and data about other mental health services in the catchment areas of the hospitals have been described in detail elsewhere. ${ }^{19}$ The inclusion criteria were: all in-patients in general psychiatric departments; admitted involuntarily; aged between 18 and 65 years; resident in the 
catchment area; with sufficient command of the national language; able to give informed consent. Exclusion criteria were: admission because of intoxication; primary diagnosis of dementia; transfer from another hospital.

\section{Procedures and measures}

Patients were identified by researchers through ongoing contacts with clinical staff on the wards and the relevant administrators. Clinical staff in the participating wards introduced eligible patients to a researcher, who contacted the patient within the first week of admission, provided a full explanation of the study, and asked for consent. If written informed consent was obtained, the patient was assessed. This included an assessment of psychopathological symptoms, which were taken as baseline symptom levels. Further face-to-face interviews were conducted at follow-up at 1 and 3 months after admission. Patients were recruited between July 2003 and October 2005.

The primary outcome was the patients' retrospective view on the extent to which the admission was right or wrong at 1 and 3 months. Patients rated their response to the question 'Today, do you find it right or wrong that you were admitted to hospital?' on an 11-point Likert scale ranging from 0 (entirely wrong) to 10 (entirely right), which has been used in previous research. ${ }^{14,15}$

Baseline sociodemographic and clinical characteristics and the diagnosis of the patients were obtained from medical records. These included data on age, gender, living situation (living alone $v$. living with others), employment situation (no current employment $v$. employment), previous hospitalisations (none $v$. one or more previous hospitalisations) and clinical diagnosis according to ICD-10. ${ }^{20}$ Diagnoses were collapsed into three groups: schizophrenia or other psychosis (F20-29), affective disorder (F30-39), and 'others'. Researchers assessed baseline symptom levels on the 24-item version of the Brief Psychiatric Rating Scale (BPRS) ${ }^{21}$ which ranges from 24 to 168 , with 168 indicating the maximum symptom severity. Researchers from all sites had joint training sessions in administering and rating this instrument and achieved an interrater reliability (intraclass correlation coefficient) of 0.78 . The study was approved by the relevant national and/or local ethics committees.

\section{Statistical analysis}

The outcome variable was the patients' retrospective view on the extent to which the admission was right or wrong on an 11-point scale ( 0 , entirely wrong; 10 , entirely right), and was treated as quantitative in the analysis to fully utilise the variation in patient's responses and summarised by mean and standard deviation after examining its distribution. To present the primary outcome in each country in a clinically more meaningful manner, we also dichotomised the scale at five (the neutral middle point) and show the percentage of patients who rated above five indicating that they viewed their admission as more right than wrong. Descriptive summary statistics were also used to describe the distributions of the predictors of the outcome variable.

To account for possible correlations among repeated measurements, a generalised estimating equation (GEE) model was employed $^{22}$ with patients' characteristics measured at baseline and time of measurement as fixed effects and patient as random effect. We performed GEE model analysis in three steps. First, we performed a univariate GEE model analysis for all predictors. Predictor variables that were significant at $P=0.05$ were subsequently entered in a multivariate GEE model analysis in the second step. Finally, we checked model assumptions by examining the residual plots.
The estimated effects of predictors on the primary outcome from the GEE models are reported together with their 95\% confidence intervals. To identify the between-country differences, we derived a matrix of $P$-values for all possible pair-wise betweencountry comparisons from the estimated multivariate GEE model.

In England, age, gender, and clinical diagnosis were obtained for all eligible patients in the study including those who were not interviewed (approved by the Patient Information Advisory Group; ref: PIAG 2-10(d)/2005). Interviewed and non-interviewed patients were compared on the assessed characteristics to estimate a potential selection bias in the recruitment process.

\section{Results}

\section{Sample characteristics}

A total of 2326 patients were recruited in all countries and assessed at baseline. Table 1 shows the number of eligible patients and the selection process in each country.

Between 31 and $71 \%$ of eligible patients were interviewed within the first week of admission, and of these between 63 and $96 \%$ were followed up at 1 month, and between 55 and $93 \%$ at 3 months.

The characteristics of the participating patients are summarised in Table 2. Overall, $72 \%$ of patients were without employment, $66 \%$ lived alone, $71 \%$ had been hospitalised before and $62 \%$ were diagnosed with schizophrenia.

At the English site, baseline data were obtained for 181 out of those 183 patients who were eligible but not interviewed. Their mean age was 36.01 years (s.d.=11.41). Of these, $40 \%$ were female, $60 \%$ diagnosed with schizophrenia, $22 \%$ with affective disorders and $18 \%$ with 'other' diagnoses. The interviewed and non-interviewed patients were similar on the tested characteristics listed in Table 2.

The baseline characteristics of patients in the total sample followed up at 1 month (and at 3 months) were: $45.1 \%$ (45.5\%) female; $73.1 \%(72.2 \%)$ unemployed; $35.3 \%$ (36.0\%) living with others; $71.4 \%(72.3 \%)$ with a previous hospitalisation; $65.7 \%$ $(64.7 \%)$ diagnosed with schizophrenia, $16.7 \%$ (17.2\%) with affective disorders and $17.6 \%(18.1 \%)$ with 'other' diagnoses. The mean age of those followed up at 1 month was 38.87 years (s.d. $=11.21)$, and of those followed up at 3 months 39.10 years $($ s.d. $=1.13)$. The baseline BPRS mean score of those followed up at 1 month was 54.77 (s.d. $=15.84$ ) and of those followed up at 3 months 55.08 (s.d. $=15.84$ ). The assessed characteristics of the originally recruited sample and the samples followed up at 1 and 3 months were similar.

\section{Patients' views on whether admission was right}

Table 3 shows the percentage of patients who thought that the admission was right, as well as the means and standard deviations of their ratings for each country and each follow-up.

In the total sample, 55\% thought at 1 month that their admission was right and $63 \%$ at 3 months. The percentages varied between 39 and $71 \%$ at 1 month, and between 46 and $86 \%$ at 3 months.

Across all countries, the distribution of the scores on the 11point rating scale at 1 month (and 3 months) were: 0: 7\% (13\%); 1: $3 \%$ (2\%); 2: 5\% (4\%); 3: 4\% (5\%); 4: 3\% (3\%); 5 : $12 \%(11 \%)$; $6: 5 \%(5 \%) ; 7: 8 \%(9 \%), 8: 12 \%(13 \%) ; 9: 9 \%$ (12\%); $10: 22 \%(24 \%)$.

\section{Factors associated with patients' views}

The univariate associations of all considered predictor variables including country of site with the outcome and the findings of 


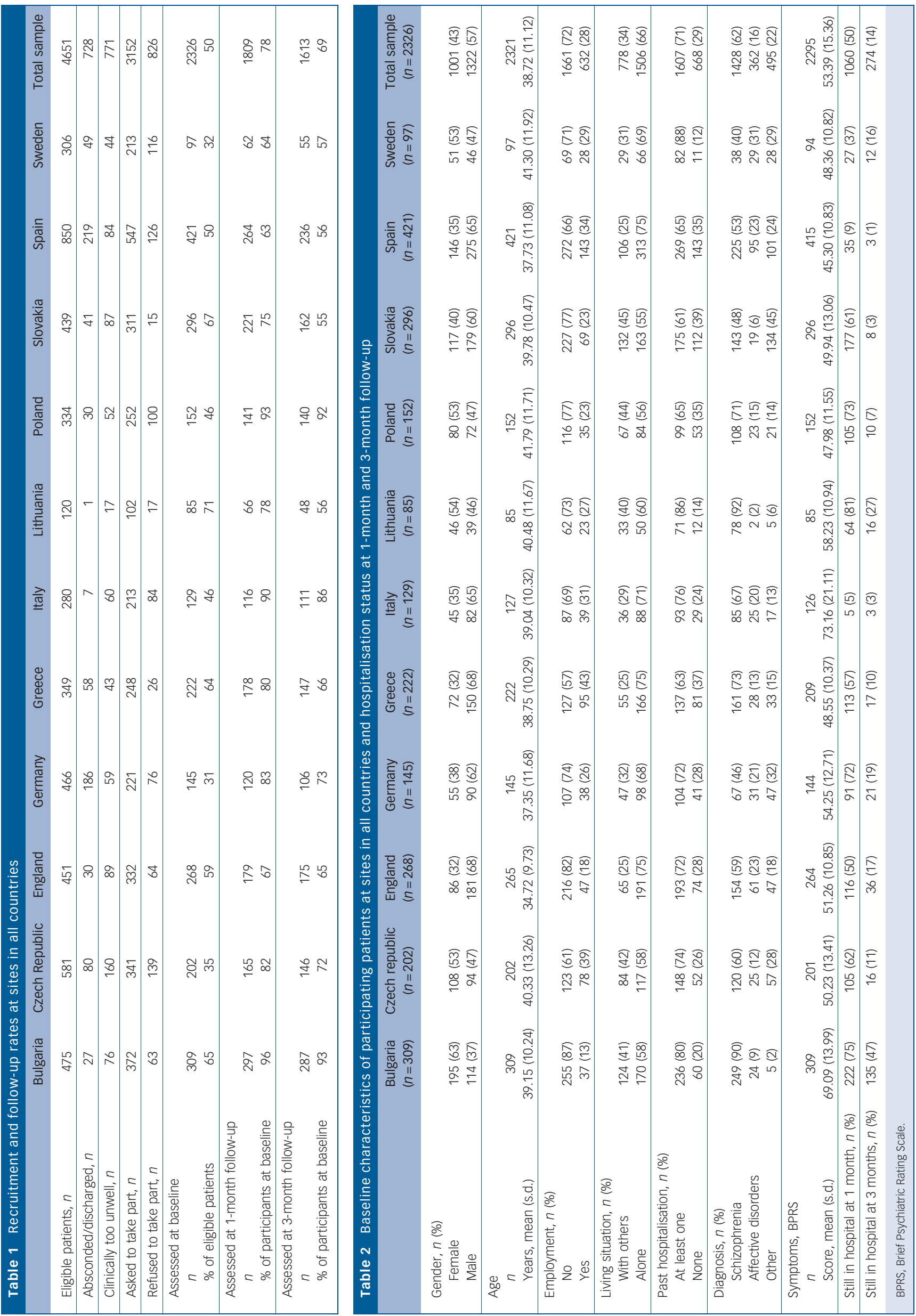




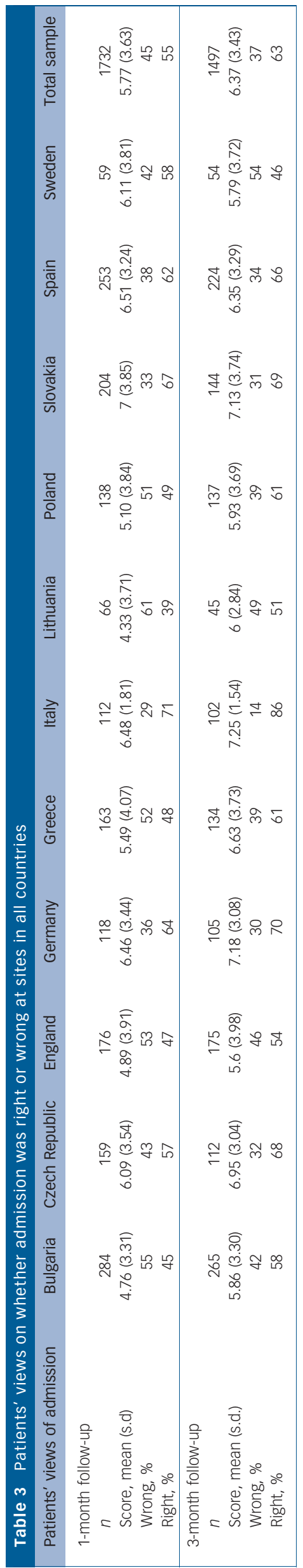

the multivariate analysis are shown in Table 4. Table 5 shows which differences between countries were significant in pair-wise post hoc comparisons, adjusting for the influence of all other significant predictor variables.

Patients' views on the appropriateness of their involuntary admission show significant differences between sites in different countries, even when adjusted for other predictor variables. The post hoc comparisons show that not all differences between sites in different countries were statistically significant, but the more substantial ones were, for example, patients' views in England are significantly less favourable than those in Bulgaria, Greece, Spain, the Czech Republic, Italy, Germany and Slovakia, whereas patients' views in Slovakia are significantly more positive than in all sites other than those in the Czech Republic, Italy and Germany.

All predictor variables considered further other than previous hospitalisation showed significant associations with outcomes in univariate analyses. In the multivariate analysis however, only gender, living situation and diagnosis were significantly associated with patients' views. Male patients and those living with others tended to find the admission more often right. Patients with schizophrenia had more negative views than those with other diagnoses.

\section{Discussion}

\section{Main findings}

One month after involuntary hospital admission, between 39 and $71 \%$ believed the admission was right. After 3 months, when the acute phase of the mental illness justifying the involuntary admission should be overcome for most patients, the rates are higher and range between 46 and $86 \%$. The findings that a substantial proportion of patients do not agree retrospectively with the appropriateness of the admission may shed a critical light on the ethical justification of involuntary hospital admission. At the same time, an average of $63 \%$ found the admission right 3 months later which may be a reassuring finding for many clinicians, patients and their families. The figures are consistent with previous studies with smaller samples and usually less systematic methods. ${ }^{6,14,23,24}$ However, what is a totally new finding is the large variation across sites in different European countries. This variation is not explained by differences in sociodemographic characteristics, clinical diagnoses or baseline symptom levels considered in this study. The size of the differences are substantial, and many of them are statistically significant.

\section{Strengths and limitations}

This is the largest prospective study on outcomes of involuntary hospital admissions ever conducted and the first one to use the same methods across sites in a number of countries. It included centres in 11 European countries with different legislation and practice in involuntary admission. All patients were assessed face to face by trained researchers, and were recruited and interviewed within the first week of admission, which is challenging given that many patients had high symptom levels and all of them were in the hospital on an involuntary basis.

The study has a number of weaknesses: overall, only $50 \%$ of the eligible patients were interviewed, and the rate varied across countries. The rate may be seen as low in many other fields of health research, but has been described as good for these types of studies in acute settings with patients who are difficult to recruit. ${ }^{6}$ For comparison of recruited and non-recruited patients, data were only available for the English site, although both the followed up and non-followed up patients were compared at all sites. These 


\begin{tabular}{|c|c|c|c|c|c|c|}
\hline \multirow[b]{2}{*}{ Predictor variables } & \multicolumn{3}{|c|}{ Univariate analysis } & \multicolumn{3}{|c|}{ Multivariate analysis } \\
\hline & $B^{a}$ & $95 \% \mathrm{Cl}$ & $P$ & $B^{\mathrm{a}}$ & $95 \% \mathrm{Cl}$ & $P$ \\
\hline \multicolumn{7}{|l|}{ Country } \\
\hline England & 0.00 & & & 0.00 & & \\
\hline Lithuania & -0.10 & -0.98 to 0.77 & 0.817 & 0.04 & -0.84 to 0.93 & 0.923 \\
\hline Poland & 0.29 & -0.37 to 0.96 & 0.391 & 0.25 & -0.41 to 0.93 & 0.454 \\
\hline Bulgaria & 0.04 & -0.51 to 0.60 & 0.882 & 0.64 & 0.02 to 1.27 & 0.041 \\
\hline Sweden & 0.77 & -0.09 to 1.63 & 0.080 & 0.77 & -0.11 to 1.65 & 0.086 \\
\hline Greece & 0.63 & -0.00 to 1.27 & 0.051 & 0.61 & -0.03 to 1.27 & 0.064 \\
\hline Spain & 1.26 & 0.69 to 1.83 & $<0.001$ & 0.43 & 0.03 to 0.84 & $<0.001$ \\
\hline Czech Republic & 1.22 & 0.57 to 1.88 & $<0.001$ & 1.19 & 0.53 to 1.85 & $<0.001$ \\
\hline Italy & 1.64 & 0.92 to 2.36 & $<0.001$ & 1.47 & 0.70 to 2.24 & $<0.001$ \\
\hline Germany & 1.49 & 0.79 to 2.19 & $<0.001$ & 1.30 & 0.60 to 2.01 & $<0.001$ \\
\hline Slovakia & 1.92 & 1.31 to 2.52 & $<0.001$ & 1.74 & 1.13 to 2.36 & $<0.001$ \\
\hline Male $v$. female & 0.77 & 0.47 to 1.06 & $<0.001$ & 0.77 & 0.46 to 1.08 & $<0.001$ \\
\hline Employed v. unemployed & 0.44 & 0.11 to 0.77 & 0.008 & 0.17 & -0.16 to 0.51 & 0.307 \\
\hline Living alone $v$. living with others & -0.56 & -0.87 to -0.26 & $<0.001$ & -0.69 & -1.02 to -0.37 & $<0.001$ \\
\hline \multicolumn{7}{|l|}{ Diagnosis } \\
\hline Schizophrenia & 0.00 & & & 0.00 & & \\
\hline Affective disorder & 0.70 & 0.30 to 1.10 & 0.001 & 0.60 & 0.19 to 1.01 & 0.004 \\
\hline Other & 0.84 & 0.45 to 1.22 & $<0.001$ & 0.43 & 0.03 to 0.84 & $<0.001$ \\
\hline BPRS score & -0.01 & -0.01 to -0.00 & 0.035 & 0.00 & -0.00 to 0.01 & 0.517 \\
\hline No past hospitalisation & 0.17 & -0.15 to 0.50 & 0.286 & & & \\
\hline
\end{tabular}

\begin{tabular}{|c|c|c|c|c|c|c|c|c|c|c|}
\hline & England & Lithuania & Poland & Bulgaria & Sweden & Greece & Spain & Czech Republic & Italy & Germany \\
\hline Lithuania & 0.923 & & & & & & & & & \\
\hline Poland & 0.454 & 0.648 & & & & & & & & \\
\hline Bulgaria & 0.041 & 0.165 & 0.257 & & & & & & & \\
\hline Sweden & 0.086 & 0.190 & 0.272 & 0.781 & & & & & & \\
\hline Greece & 0.064 & 0.213 & 0.311 & 0.932 & 0.738 & & & & & \\
\hline Spain & $<0.001$ & 0.012 & 0.005 & 0.100 & 0.376 & 0.082 & & & & \\
\hline Czech Republic & $<0.001$ & 0.013 & 0.009 & 0.102 & 0.363 & 0.097 & 0.909 & & & \\
\hline Italy & $<0.001$ & 0.004 & 0.004 & 0.021 & 0.170 & 0.036 & 0.419 & 0.497 & & \\
\hline Germany & $<0.001$ & 0.008 & 0.006 & 0.059 & 0.264 & 0.064 & 0.659 & 0.759 & 0.694 & \\
\hline Slovakia & $<0.001$ & $<0.001$ & $<0.001$ & $<0.001$ & 0.029 & 0.001 & 0.043 & 0.089 & 0.477 & 0.209 \\
\hline
\end{tabular}

comparisons did not suggest a selection bias on the assessed characteristics, neither for the recruitment of eligible patients nor for the follow-ups. However, only a few characteristics were assessed.

We only studied between one to five hospitals in each country and do not know to what extent the data are representative for the country as a whole. In England we have data from a linked national study to estimate this. ${ }^{24}$ The English sites in this international study were two hospitals in the London boroughs of Hackney and Newham. In 20 other hospitals, the same outcome data were assessed in 371 involuntary patients at 1 month and in 307 patients at 3 months. At 1 month, $45 \%(n=166)$ of patients felt that the admission was right (mean score 4.81, s.d. $=3.99)$, and at 3 months $50 \%(n=154)$ expressed that view (mean score 5.34, s.d.=3.94). Outcomes at the two study-site hospitals in east London and the 20 other hospitals in England were similar, and using the data of those 20 hospitals would not have substantially changed the findings of the national comparisons. However, there are no similar data from other countries to check whether the results at the study sites are representative for or different from the outcomes at other hospitals in the country.

\section{Possible reasons for the differences}

Can the identified differences in patients' views about involuntary admission be linked to the characteristics of the given legislation? There is no straightforward answer. The legislation in all countries is complex and has many features that are of potential importance. Any interpretation of the findings from the identified differences with the characteristics of the national legislation is a post hoc exercise and inevitably speculative.

One possible criterion to classify the national regulations is the extent to which they protect the rights and interests of the patients concerned. ${ }^{8,9}$ Seven criteria that vary between countries and may be seen as relevant for the protection of the interests of the patients are shown in the Appendix. Although the answers to the questions are not always clear cut, we established the number 
of criteria for each country. The resulting ranking has similarities with the order of outcomes in the multivariate analysis of this study (with the most protective legislation and most positive patient views in Slovakia and Germany, and the least protective legislation and most negative views in England), but the criteria still leave many of the differences in patients' views unexplained.

A number of other national features might be important. These include the geographical position and political history (e.g. Western $v$. Eastern Europe), the relative expenditure of healthcare funding on mental healthcare, ${ }^{25}$ the overall rates of involuntary admissions, ${ }^{2}$ and the recruitment and follow-up rates in this study. However, none of these was clearly associated in our study with the differences identified in patients' views. There are three other possible factors accounting for the differences that were not assessed. First, patients at the various sites may have differed in relevant social or clinical characteristics that were not captured in the study. Second, national differences in the expectations of patients and overall rating tendencies may have favoured more or less positive answers to the outcome question. Finally, clinical practice (the behaviour of professionals towards involuntary patients and the methods employed to support and treat them) is likely to vary across Europe and impact on outcomes. Some aspects of clinical practice may be linked to national cultures and traditions and difficult to change, but others may reflect training and policies that are transferable to other countries.

\section{Factors associated with outcomes across countries}

Some patient characteristics were associated with views on admission across countries. Females expressed more negative views, as has been reported for other patient-reported outcomes in psychiatry, although this is not a consistent finding. ${ }^{26,27}$ Patients living alone more often rated the admission as wrong, which may reflect their difficulties adjusting to the confined space and the often tense atmosphere with fellow patients and staff on a ward. It may also be that patients living with others had often experienced conflicts and tension with these making the admission a relief and therefore the right decision in retrospect. During and after hospital treatment they are likely to have had discussions with their partners about their illness and received support from them. Both discussions and support may have led to more positive appraisals of the admission. Patients with schizophrenia had more negative views on admission, which may be linked to a more frequent lack of insight in these patients. ${ }^{28}$ In the multivariate analysis, the degree of baseline symptoms was not associated with later views about the admission. Thus, this study provides no evidence for the assumption that a high level of initial symptoms is associated with more negative views about admission later.

\section{Implications}

The findings suggest that the great differences in the legislation and practice of involuntary hospital admission and subsequent treatment across Europe may indeed be associated with substantial differences in patients' views. Although the exact causal factors and mechanisms remain poorly understood, the differences between European countries appear to matter for outcome. ${ }^{29}$ Future in-depth studies could identify those factors in legislation and practice that are specifically relevant to achieving more positive views from patients. ${ }^{30}$ Countries with currently less favourable outcomes, such as England, might consider implementing them, and methods may be developed to strengthen these factors and improve outcomes across all countries.
Stefan Priebe, FRCPsych, Christina Katsakou, PhD, Unit for Social and Community Psychiatry, Barts' and the London School of Medicine and Dentistry, Queen Mary University of London, UK; Matthias Glöckner, Dipl-Psych, Department for Psychiatry and Psychotherapy, University Hospital Carl Gustav Carus, Dresden University of Technology, Germany; Algirdas Dembinskas, MD, Vilnius University Psychiatric Clinic, Lithuania; Andrea Fiorillo, MD, PhD, Department of Psychiatry, University of Naples, Italy; Anastasia Karastergiou, MD, PhD, Acute Ward, Psychiatric Hospital of Thessaloniki, Greece; Andrzej Kiejna, MD, PhD, Department of Psychiatry, Wroclaw Medical University, Poland; Lars Kjellin, Dr Med Sc, School of Health and Medical Sciences, Psychiatric Research Centre, Örebro University, Sweden; Pìtr Nawka, MD, Psychiatric Oupatient Clinik, Dresden, Germany; George Onchev, MD, PhD, Department of Psychiatry, Medical University Sofia, Bulgaria; Jiri Raboch, MD, Psychiatric Department, Charles University in Prague, 1st Medical School, Czech Republic; Matthias Schuetzwohl, PhD, Department for Psychiatry and Psychotherapy, University Hospital Carl Gustav Carus, Dresden University of Technology, Germany; Zahava Solomon, PhD, Adler Research Center and Tel Aviv University, Israel; Francisco Torres-González, MD, PhD, Centro de Investigación Biomedica en Red de Salud Mental (CIBERSAM), University of Granada, Spain; Duolao Wang, PhD, Department of Epidemiology and Population Health, London School of Hygiene and Tropical Medicine, London, UK; Thomas Kallert, MD, Department of Psychiatry and Psychotherapy, Faculty of Medicine, Dresden University of Technology; Department of Psychiatry, Psychosomatic Medicine and

Psychotherapy, Park Hospital Leipzig; and Soteria Hospital Leipzig, Germany

Correspondence: Stefan Priebe, Academic Unit, Newham Centre for Mental Health, London E13 8SP, UK. Email: s.priebe@qmul.ac.uk

First received 27 May 2009, final revision 13 Oct 2009, accepted 28 Oct 2009

\section{Funding}

This study was funded by a grant from the European Commission (Quality of life and Management of Living Resources Programme, contract number QLG4-CT-2002-01036).

\section{Acknowledgements}

We are grateful to all the patients we interviewed and the staff at the participating hospitals. We also thank all the researchers involved in data collection.

\section{Appendix}

\section{Criteria to distinguish the legislation on involuntary hospital admission with respect to the protection of the interest of the patients}

For each question the first option is seen as more protective of the interest of the patients.

\section{Legislation criteria}

(a) Is involuntary admission possible only when patients pose a risk to themselves and/or others, or also to avoid a more general threat to the patients' health?

(b) Can the admission be initiated only by authorities and medical doctors or also by other stakeholders?

(c) Does involuntary admission require the decision of a court or not?

(d) Is the period of time for which the hospital can decide to keep patients involuntarily on the wards without a formal decision for involuntary treatment shorter or longer than 24 hours?

(e) Is legal support guaranteed or not?

(f) With respect to appeal procedures to independent bodies, are there binding time periods for a response, and are people and/or institutions other than the patient authorised to appeal, or not?

(g) Is the decision for involuntary treatment measures separate from the decision for involuntary admission or not?

\section{Criteria protecting the interest of the patients in each country}

Seven: Germany (a-g)

Five: Slovakia (a, c, d, f, g), Sweden $(a, b, d, e, f)$.

Four: Bulgaria (a, c, d, g), Czech Republic (a, c, d, g), Spain (c, d, e, g).

Three: Italy $(b, f, g)$, Poland (b, $c, e)$, Lithuania $(a, b, c)$.

Two: Greece (c, f)

One: England (e). 


\section{References}

1 Zinkler M, Priebe S. Detention of the mentally ill in Europe - a review. Acta Psychiatr Scand 2002; 106: 3-8.

2 Salize HJ, Dressing H. Epidemiology of involuntary placement of mentally ill people across the European Union. Br J Psychiatry 2004; 184: 163-8.

3 Welsh S, Deahl MP. Modern psychiatric ethics. Lancet 2002; 359: 253-5.

4 Zigmond T. A new Mental Health Act for England and Wales. Adv Psychiatr Treat 2004; 10: 161-3

5 Tilley S, Chambers M. Proposed changes to the Mental Health Act of England and Wales - research investigating the debate. J Psychiatr Ment Health Nurs 2005; 12: 121-3.

6 Katsakou C, Priebe S. Outcomes of involuntary hospital admission - a review. Acta Psychiatr Scand 2006; 114: 232-41.

7 Kallert TW, Glöckner M, Schutzwohl M. Involuntary vs. voluntary hospital admission: a systematic literature review on outcome diversity. Eur Arch Psychiatry Clin Neurosci 2008; 258: 195-209.

8 Felthouse A, Sass H. The International Handbook of Psychopathic Disorders and the Law Vol II: Law and Policies. John Wiley \& Sons, 2008

9 Kallert TW, Torres-Gonzalez F. Legislation on Coercive Mental Health Care in Europe. Peter Lang Publications, 2006.

10 Kallert TW, Rymaszewska J, Torres-Gonzalez F. Differences of legal regulations concerning involuntary psychiatric hospitalisation in twelve European countries: implications for clinical practice. Int J Forensic Ment Health 2007; 6: 197-207.

11 Beck JC, Golowka EA. A study of enforced treatment in relation to Stone's 'thank you' theory. Behav Sci Law 1988; 6: 559-66.

12 Spence ND, Goldney RD, Costain WF. Attitudes towards psychiatric hospitalization: a comparison of involuntary and voluntary patients. Aust Clin Rev 1988: 8: 108-16.

13 Towes J. Change with time in patients' reactions to committal. Can J Psychiatry 1986; 31: 413-5.

14 Kjellin L, Westrin CG, Eriksson K, Alexsson-Ostman M. Coercion in psychiatric care: problems of medical ethics in a comprehensive empirical study. Behav Sci Law 1993; 11: 323-34.

15 Kjellin L, Anderson K, Bartholdson E, Candefjord IL, Holmstrom H, Jacobsson, et al. Coercion in psychiatric care - patients' and relatives' experiences from four Swedish psychiatric services. Nord J Psychiatry 2004; 58: 153-9.
16 Kane JM, Quitkin F, Rifkin A, Wegner J, Rosenberg G, Borenstein M. Attitudinal changes of involuntarily committed patients following treatment. Arch Gen Psychiatry 1983; 40: 374-7.

17 Srinivasan DP, Soundarajan PC, Hullin RP. Attitudes of patients and relatives to compulsory admission. Br J Psychiatry 1980; 136: 200-1.

18 Rusius C. The Mental Health Act 1983 - what does the patient think? Psychiatr Bull 1992; 16: 268-9.

19 Kallert TW, Glöckner M, Onchev G, Raboch J, Karastergiou A, Solomon, et al The EUNOMIA project on coercion in psychiatry: study design and preliminary data. World Psychiatry 2005; 4: 168-72.

20 World Health Organization. The ICD-10 Classification of Mental and Behavioural Disorders: Diagnostic Criteria for Research (DCR-10). WHO, 1998

21 Ventura J, Green MF, Shaner A, Liberman R. Training and quality assurance with the Brief Psychiatric Rating Scale: 'The Drift Busters'. Int J Methods Psychiatric Res 1993; 3: 221-4.

22 Liang KY, Zeger SL. Longitudinal data analysis using generalized linear models. Biometrika 1986; 73: 13-22.

23 Kjellin L, Anderson K, Candefjord I, Palmstierna T, Wallsten T. Ethical benefits and costs of coercion in short-term inpatient psychiatric care. Psychiatr Serv 1997: 48: 1567-70.

24 Priebe $S$, Katsakou $C$, Amos $T$, Leese $M$, Morriss $R$, Rose $D$, et al Patients views and readmissions 1 year after involuntary hospitalisation. $\mathrm{Br}$ Psychiatry 2009; 194: 49-54.

25 European Commission. Improving the Mental Health of the Population. Towards a Strategy on Mental Health for the European Union. European Commission, 2005

26 Lehman AF. The effects of psychiatric symptoms on quality of life assessments among the chronically mentally ill. Eval Program Plann 1983; 6: $143-51$.

27 Vandiver VL. Quality of life, gender and schizophrenia: a cross-nationa survey in Canada, Cuba and the USA. Community Ment Health J 1998; 34: $501-52$

28 Dinos S, Stevens S, Serfaty M, Weich S, King M. Stigma: the feelings and experiences of 46 people with mental illness. Qualitative study. Br J Psychiatry 2004; 184: 176-81.

29 Priebe S, Frottier P, Gaddini A, Kilian R, Lauber C, Martínez-Leal R, et al Mental health care institutions in nine European countries, 2002 to 2006. Psychiatr Serv 2008; 59: 570-3.

30 Katsakou C, Priebe S. Patients' experiences of involuntary hospital admission and treatment: a review of qualitative studies. Epidemiol Psichiatr Soc 2007: 16: $172-8$.

\section{Psychiatrists in 19th-century fiction}

\section{Passages from the Diary of a Late Physician (1837), Samuel Warren}

\section{Fiona Subotsky}

Samuel Warren (1807-1877) was a lawyer who eventually achieved the well-rewarded post of Master of Lunacy with responsibility to adjudicate on the financial affairs of lunatics. When younger, he had also for 6 years 'actively engaged in the practical study of physic', perhaps as apprentice to an apothecary. His many tales, published first in Blackwood's Magazine, inspired imitation from Poe, Le Fanu and Dickens, and concentrated on sensational medical case histories, especially including the supernatural, insanity and deathbeds, ideally all three, as below.

In The Spectre-Smitten, law student Mr M returns to gloomy Lincoln's Inn after a night of revelry, to find a figure of 'ghastly hue' sitting in his armchair, which then terrifyingly stretches out its arms and approaches. Mr M falls 'senseless on the floor', proceeding to frequent convulsions, twitchings and contortions. He recovers consciousness, but learning that his neighbour died on the night of the apparition becomes convinced he is haunted by him. The physician forms the opinion that Mr $\mathrm{M}$ is 'suffering from a very severe congestion of the vessels of the brain', and orders 'copious venesection - his head to be shaven, and covered perpetually with cloths soaked in evaporating lotions - blisters behind his ears and at the nape of the neck - and appropriate internal medicines'. This fails to prevent an attempted murderous assault with a razor after which the patient is put in a strait jacket, strapped to a bed, and removed to an asylum 'reduced to a state of drivelling idiocy - complete fatuity!' Even though Mr M improves somewhat, he is still convinced, despite the physician trying to reason with him, that he is constantly under the watch of a huge boa constrictor. Apparent recovery notwithstanding, he later destroys himself 'in a manner too terrible to mention'.

This is one of the more coherent stories. It is best if the reader can just relax and enjoy shock by shock, hoping that current interventions have made progress. 